\title{
Transduction of fibroblasts and CD34+ progenitors using a selectable retroviral vector containing cDNAs encoding arylsulfatase A and CD24
}

\begin{abstract}
Metachromatic leukodystrophy (MLD) is an autosomal recessive, inherited, lysosomal storage disease caused by a deficiency in arylsulfatase A (ASA). This disease is characterized by progressive demyelination leading to severe neurological symptoms. Allogenic bone marrow transplantation at an early stage of clinical course is only effective treatment currently available. Accordingly the corrective transfer of the ASA gene into hematopoietic stem cells is thought to be an important option for curative treatment for MLD. We have recently developed a selectable vector system based on ex vivo sorting of transduced cells (Migita et al. 1995). In this study, we applied this selectable system for development of MLD gene therapy. A bicistronic retroviral vector containing ASA cDNA and CD24 cDNA as a selectable marker gene was constructed. This vector was successfully transduced on fibroblasts from MLD patients, ASA activity was increased 7-fold compared to normal untransduced cells. PCR Southern analysis of hematopoietic colonies showed that transduction efficiency of CD34+ cells was $11-22 \%$. However, after fluorescenceactivated cell sorting using anti-CD24 antibody, $75-100 \%$ of colonies became vector positive. The sorting raised the ASA activity several fold compared to untransduced CD34+ progenitors. These results suggest that a bicistronic ASA vector containing a CD24 selectable marker could be a useful component of gene therapy for MLD.
\end{abstract}

Key words Gene therapy · Metachromatic leukodystrophy - Arylsufatase A · Retroviral vector · Human CD24 · Selectable marker

A. Tsutsuda-Asano $\cdot$ M. Migita $(\bowtie) \cdot K$. Takahashi $\cdot$ T. Shimada Department of Biochemistry and Molecular Bilogy, Nippon Medical School, 1-1-5 Sendagi, Bunkyo-ku, Tokyo 113-8602, Japan

Tel. +81-3-3822-2131; Fax +81-3-5814-8156

e-mail: Makoto_Migita/bmb@nms.ac.jp

\section{Introduction}

Metachromatic leukodystrophy (\#250100, MLD) is a lysosomal storage disease, caused by deficiency of arylsulfatase A (EC 3.1.6.8., ASA) which hydrolyses cerebroside sulfate (Kolodny and Fluharty 1995). The disease is characterized by accumulation of cerebroside sulfate in oligodendrocytes in the brain resulting in demyelination. No effective therapy, other than the allogenic bone marrow transplantation (BMT), has been developed, and without BMT, patients usually die within a decade after the first appearance of the clinical symptoms. Earlier reports strongly asserted that it was crucial to perform BMT at a presymptomatic stage of MLD, to expect the best possible neurological outcome (Krivit et al. 1995; Hoogerbrugge et al. 1995; Malm et al. 1996). Although the rationale of BMT in lysosomal storage diseases is not completely clear, one possibility appears to be cross-correction by transfer of normal enzyme from the donor cells to the deficient cells (Neufeld 1991; Olsen et al. 1981). Unfortunately, HLA-matched donors are frequently difficult to find. This has made gene therapy strategy that targets hematopoietic stem cells (HSC), using autologous BMT, advantageous.

Gene transfer experiments using various viral vectors containing the $A S A$ gene have been attempted (Rommerskirch et al. 1991; Ohashi et al. 1995; Learish et al. 1996). Oligodendrocytes are important targets for gene therapy of MLD. However, there are many difficulties in stable gene transfer into neuronal cells at present. Retroviral mediated gene transfer into human HSC is an important option, but its efficiency remains very low. An alternative approach has been to develop methods for selecting transduced cells from non-transduced cells, using a selectable marker. We have developed a novel system in which a bicistronic retroviral vector, containing a surface antigen (human CD24) that serves as a selectable marker (Kay et al. 1991; Pawliuk et al. 1994), is used to efficiently select transduced cells without exposure to the cytotoxic agents such as neomycin (Migita et al. 1995). Because 
there was very good correlation between expression of therapeutic and marker genes, it was possible to select only genetically modified cells prior to transplantation therapy. This success has led us to search other target diseases. In the present study, we tested the ability to deliver the ASA gene into HSCs using a bicistronic selectable retroviral vector.

\section{Materials and methods}

\section{Vector Construction}

A plasmid pBEH/HT14-CP8 containing human $A S A$ cDNA was a generous gift from Dr. Gieselmann (University of Kiel, Kiel, Germany; Stein et al. 1989). The ASA cDNA fragment was isolated from pBEH/HT14-CP8 by EcoRI digestion, blunt ended, and modified with XhoI linkers. This XhoI fragment was inserted into the XhoI site of pG1EC, which is a MoMLV-based vector plasmid bearing an internal ribosomal entry site (IRES) from the long 5'untranslated region of encephalomyocarditis virus (EMCV), and human CD24 cDNA fragment between 5'and 3'- long terminal repeats (LTR) (Migita et al. 1995). The resulted plasmid was named as pASAEC.

Cell Culture, viral producer cells, and fluorescenceactivated cell storer (FACS)

Transient ecotropic virus-producer cells BOSC23 (Pear et al. 1993), amphotropic virus producer cells GP + envAM12, and NIH3T3 cells (American Type Culture Collection, Rockville, MD, USA) were maintained in Dulbecco's Modified Eagle Medium (DMEM) supplemented with $10 \%$ fetal bovine serum (FBS), penicillin (100 units/ml), streptomycin $(100 \mathrm{mg} / \mathrm{ml})$ and $10 \mathrm{mg} / \mathrm{ml}$ of glutamine. Skin fibroblasts from the patients with MLD, which were a kind gift from Dr. Sakuragawa (National institute of Neurology and Psychiatry, Tokyo, Japan), were cultured in the same media but containing $15 \%$ FBS. High-titer amphotropic virusproducing GP+envAM12 cells were created by multiple infections with ecotropic virus supernatants from BOSC23 cells transfected with pASAEC. These transduction procedures were repeated 15 times, and cells expressing high CD24 level were selected by fluorescence-activated cell sorter (FACS; FACS Caliber, Becton Dickinson, Tokyo, Japan) for efficient cloning. To detect the CD24 expression, transduced cells $(1 \times 106)$ were labeled with FITC-conjugated anti-CD24 antibody (Accurate Chemical \& Scientific Co., NY, USA) then sorted from untransduced cells by FACS. At the last step, the highest-titer clone was selected by FACS again from 50 colonies cloned. The titer was determined by Southern blot analysis of transduced 3T3 cells to estimate proviral copy number in the target cells. Viral titers were expressed as copies per transduced NIH3T3 cells per ml of vector supernatant.
Transduction to the target cells

NIH3T3 cells were transduced once with $1 \mathrm{ml}$ of viral supernatants and $9 \mathrm{ml}$ of standard medium with $4 \mathrm{mg}$ of protamine sulfate (Elkins-Sinn, Cherry Hills, NJ, USA). MLD skin fibroblasts were infected four times, on consecutive days, with $5 \mathrm{ml}$ of viral supernatant and protamine sulfate. $\mathrm{Hu}$ man CD34+ hematopoietic progenitor cells were isolated from cord blood by Dynal CD34 progenitor cell selection system (Dynal, Oslo, Norway) and transduced with the viral supernatant, protamine sulfate, Interleukin (IL)-3 (Kirin Brewers Co., Tokyo Japan), IL-6 (Kirin), and stem cell factor (SCF) (Amgen, Thousand oaks, CA, USA) for 4 consecutive days, as previously described (Xu et al. 1995).

\section{Measurement of ASA enzyme activity}

Cultured cells were harvested and washed twice in cold phosphate-buffered saline (PBS). They were then sonicated in double-distilled water, then centrifuged to eliminate cellular debris. After quantifying of protein using the Bradford protein assay (Bio-Rad, Tokyo, Japan), ASA enzyme activity were measured by colorimetric assay utilizing p-nitrocatechol sulfate (Sigma, St. Louis, MO, USA) as a substrate, originally described previously (Baum et al. 1959).

The activity was described as $\mathrm{mg}$ of 4-nitrocatechol/mg of total protein per $h$.

Colony-PCR analysis for CD34+ derived hematopoietic colonies

Colonies grown for two weeks on methylcellulose containing GM-CSF, SCF, IL-3 (Methocult GF4534; Stem Cell Technologies, Vancouver, Canada) were selected separately in standard PCR buffer containing $0.45 \%$ of Triton$\mathrm{X}$ and $0.45 \%$ of Nonidet P40. To extract DNA, each cell suspension was lysed by incubation for 1 hour at $55^{\circ} \mathrm{C}$ with $30 \mathrm{mg} / \mathrm{ml}$ of proteinase $\mathrm{K}$ (Boeringer Mannheim, Indianapolis, IN, USA), which was then boiled for $10 \mathrm{~min}$. The PCR primers were as follows; sense strand oligomer; $5^{\prime}$ GCACCCCAGCTCTACCACTC-3', antisense strand; 5' CACAGCCACCGTCGCAAGGA-3'. PCR was carried out at $94^{\circ} \mathrm{C}$ for $5 \mathrm{~min}$., then 30 cycles of $94^{\circ} \mathrm{C}(30 \mathrm{~s}), 55^{\circ} \mathrm{C}(30$ s), $72^{\circ} \mathrm{C}\left(1 \mathrm{~min}\right.$.); final elongation was performed at $72^{\circ} \mathrm{C}$ for $7 \mathrm{~min}$. Bands were confirmed to be specific for $A S A$ cDNA using a non-radioactive PCR-Southern hybridization procedure. Visualization on Hybond-N+ nylon membrane (Amersham Life Science, Buckinghamshire, England) was accomplished using ECL system (Amersham).

\section{Results}

Generation of high-titer, bicistronic vector producer cells

A schematic diagram summarizing the structure of the retroviral expression vector, pASAEC, is shown in Fig. 1. 


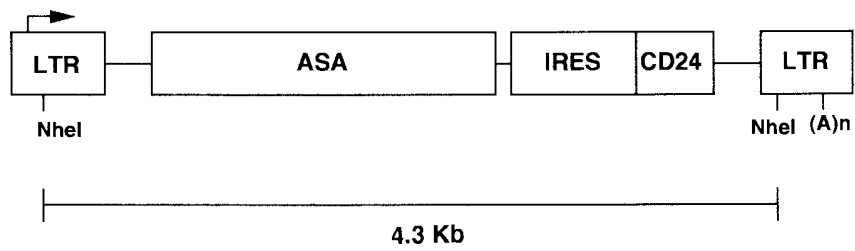

Fig. 1. Schematic diagram of retroviral bicistronic construct pASAEC. $L T R$, MoMLV LTR, ASA, ASA cDNA; IRES, internal ribosomal entry site from long $5^{\prime}$ untranslated region of EMCV; $C D 24, \mathrm{CD} 24$ cDNA; $(A) n$, polyadenylation signal; NheI, site for restriction endonuclease NheI

Expression of both the $A S A$ and $\mathrm{CD} 24$ genes was controlled by the MoMLV- LTR by placing the IRES and the CD24 selectable marker gene downstream of the ASA cDNA. Transduction of BOSC23 cells with pASAEC resulted in simultaneous high level expression of $A S A$ and CD24 (data not shown). Amphotropic recombinant retrovirus producer cells GPASAEC were generated from GP+ envAM12 cells by repeated infection with ecotropic retrovirus supernatants of BOSC23 cells transfected with pASAEC. FACS and cloning techniques were used to select 50 GPASAEC clones expressing high levels of $C D 24$. Six clones showed prominent $C D 24$ expression on FACS. To select the highest titer vector producer cell clone, viral supernatants from GPASAEC clones were incubated with NIH3T3 cells, and transduction efficiency was estimated by $C D 24$ expression with FACS analysis and ASA enzyme activity on transduced 3T3 cells. One clone, GPASAECno.13, showed the highest levels of ASA enzyme activity and CD24 expression in transduced 3T3 cells, as well as more than three proviral copies per transduced $3 \mathrm{~T} 3$ cells per $\mathrm{ml}$ of virus supernatant in comparison with copy number control samples (data not shown). Therefore, the clone no.13 was chosen as the ASAEC vector producer cells in this study.

\section{Transduction of MLD fibroblast}

Skin fibroblasts from two unrelated MLD patients were transduced with the ASAEC vector. FACS analysis revealed efficient gene transfer, with a high level of $C D 24$ marker gene expression in transduced MLD fibroblasts from both patients (Fig. 2), while untransduced MLD fibroblasts had little $C D 24$ expression. This result indicates that it is possible to neglect intrinsic $C D 24$ expression in fibroblasts, as vector ASAEC exhibited effective transduction into human MLD fibroblasts. High levels of $A S A$ activity were also detected in transduced cells; the highest value was $1366.5 \pm 6.1 \mu \mathrm{g} / \mathrm{mg}$ protein per $\mathrm{h}$, which was seven fold higher than $A S A$ activity in untransduced normal skin fibroblasts (normal value rangefrom 139.1 to $202.1 \mu \mathrm{g} / \mathrm{mg}$ protein per $h$ in our assay system)(Table 1$)$.

Transduction of human CD34+ cells

We next examined whether the ASAEC vector could be used to transduce human CD34+ cells derived from cord

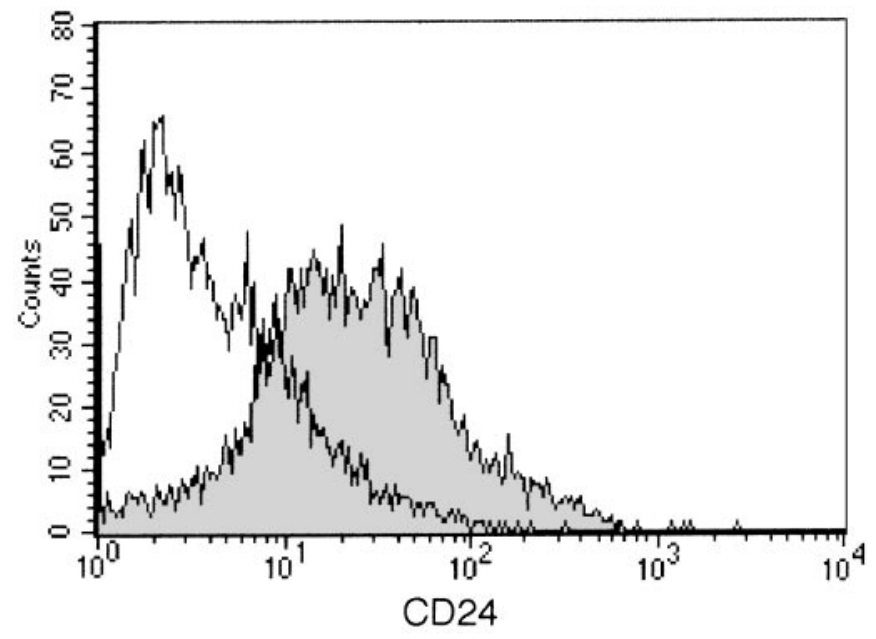

Fig. 2. $C D 24$ expression in skin fibroblasts from a patient with metachromatic leukodystrophy (MLD) transduced with the ASAEC vector. Non-shadowed area indicates non-transduced MLD fibroblasts; shadowed area indicates virus-transduced cells. Increased CD24 expression was apparent in the virus-transduced cells

Table 1. Arylsulfatase A ( $A S A)$ enzyme activity in primary skin fibroblasts from patients with metachromatic leukodystrophy (MLD) transduced with the ASAEC vector

\begin{tabular}{llc}
\hline & Before transduction & After transduction \\
\hline Patient 1 & $11.1 \pm 0.07$ & $429.7 \pm 2.05$ \\
Patient 2 & $12.1 \pm 2.48$ & $1366.5 \pm 6.08$ \\
\hline
\end{tabular}

A significant increase in $A S A$ enzyme activity was noted in the virustransduced fibroblasts (MLD fibroblast/transduced). Enzyme activity was measured in triplicate, and expressed as $\mu \mathrm{g}$ of 4-nitrocatechol $/ \mathrm{mg}$ of protein per h. $A S A$ activities of fibroblasts from non-MLD subjects ranged from 139.1 to 202.1 in our assay system

blood. Figure 3a, $\mathrm{b}$ shows representative FACS profiles of double-labeled, human hematopoietic progenitor cells on the fifth day after transduction with the ASAEC vector. Figure 3a shows the FACS profile of uninfected cells: Because these cells were maintained in the presence of IL-3, IL-6 and SCF for 4 days during the ex-vivo culture, some cells had differentiated and no longer expressed CD34. Figure $3 \mathrm{~b}$ shows the transduced CD34+ cells: Appoximately $15 \%$ of these CD34+ cells expressed CD24. The fractions were sorted based on the expression of $C D 24$ and $C D 34$. Sorted and unsorted CD34+ cells were plated on methylcellulose separately, and 2 weeks later, hematopoietic colonies were picked and individually analyzed for presence of the vector using PCR. Many colonies were pooled together for $A S A$ enzyme activity measurement. As shown in Table 2 , transduction efficiency for the complete sample of hematopoietic colonies was $11-22 \%$, whereas the efficiency among the sorted colonies was $75-100 \%$; thus, the DNA integration ratio was significantly increased by sorting based on the expression of $C D 24$. As compared with nontransduced CD34+-derived cell colonies, the $A S A$ activity in the transduced, progenitor cell-derived colonies was significantly elevated (1.7-fold) in unsorted cells and was further increased (4.5-fold) in the sorted cells (Fig. 4). 
Fig. 3a,b. CD24 expression in human $\mathrm{CD} 34+$ hematopoietic progenitor cells transduced with the ASAEC vector. CD34+/CD24+ cells (upper right quadrant) represented $14.84 \%$ of the total cell number. CD24 expression was also noted in CD34-/CD24+ cells (lower right quadrant) non-transduced

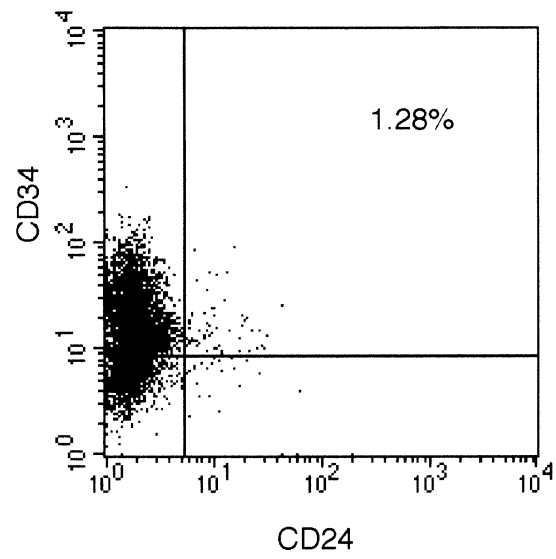

transduced

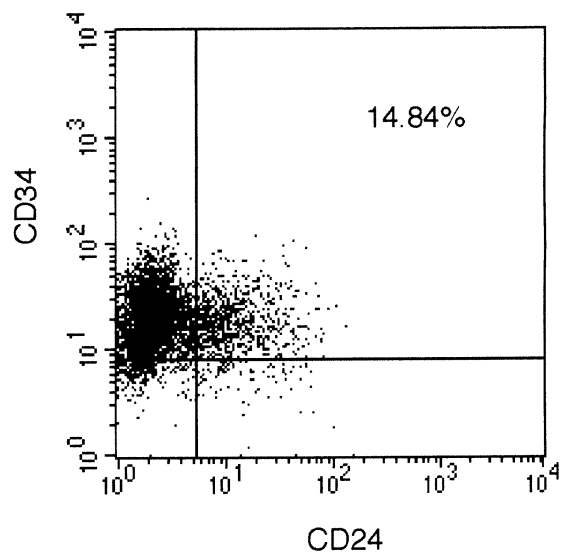

Table 2. Polymerase chain reaction (PCR) analysis of CD34+ hematopoietic colonies

\begin{tabular}{llll}
\hline & Non-transduced & $\begin{array}{l}\text { Transduced/ } \\
\text { non-sorted }\end{array}$ & $\begin{array}{l}\text { Transduced/ } \\
\text { sorted }\end{array}$ \\
\hline Experiment 1 & $0 / 3$ & $4 / 18(11 \%)$ & $8 / 8(100 \%)$ \\
Experiment 2 & $0 / 4$ & $2 / 18(22 \%)$ & $6 / 8(75 \%)$ \\
\hline
\end{tabular}

CD34+ cells were transduced with the ASAEC vector, sorted, and cultured in methylcellulose. Individual colonies were picked up, and DNA was analyzed by PCR-Southern using an $A S A$ cDNA probe. The data represent the number of colonies positive for the transduced $A S A$ gene/total colonies selected

\section{Discussion}

We report here on the successful retroviral gene delivery of the $A S A$ and $C D 24$ genes to skin fibroblasts from MLD patients and to human $\mathrm{CD} 34+$ hematopoietic progenitor cells, using a bicistronic vector. Transduced cells were readily separated from uninfected cells by FACS based on $C D 24$ expression, consequently this selectable system has the potential to be highly advantageous for the development of MLD gene therapy targeting hematopoietic progenitors. There are several reasons why gene corrected hematopoietic progenitor cells should be useful for the treatment of MLD. First, storage material may be taken up by the donor macrophages; second, hematopoietic stem cells may be able to differentiate into both microglia and macroglia in the brain (Eglitis et al. 1997); third, enzyme protein may be transferred from the donor cells to the patient's deficient cells including oligodendrocytes. Recently, Sangalli et al. reported that overexpressed $A S A$ in transduced 3T3 cells was secreted into culture medium and taken up by co-cultured MLD lymphoid cells or rat oligodendrocytes (Sangalli et al. 1999). Therefore, gene therapy involving autologous transplantation of genetically corrected bone marrow cells is an attractive approach for MLD.

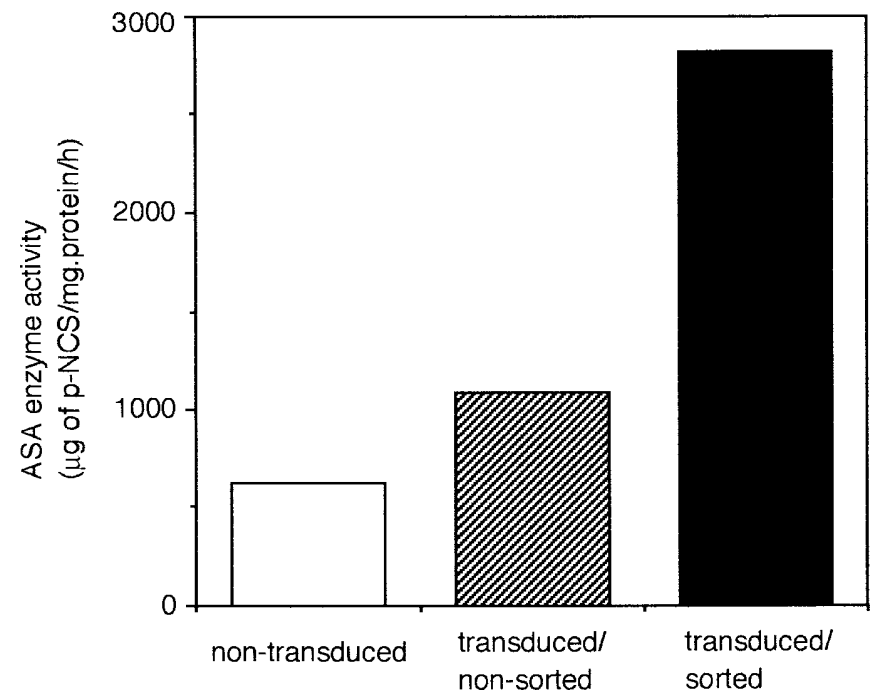

Fig. 4. $A S A$ activity in human CD34+ hematopoietic progenitor cells transduced with the ASAEC vector. A significant increase in ASA activity was noted in the virus-transduced CD 34+ cells. The activity was further increased in the CD24-sorted cells

Lately, green fluorescent protein (GFP) has been used in retroviral vector systems for the selection of transduced cells by FACS (Persons et al. 1997). As this gene has been cloned from a jellyfish, Aequorea victoriaIn (Chalfie et al. 1994), it may cause an immunological response when GFPoverexpressed cells are implanted in human. In contrast, the CD24 molecule is the human hematopoietic cell surface antigen and therefore, is immunologically inert. This appears to be an advantage of using the CD24 marker over other non-human selectable markers such as GFP, resistant genes of neomycin, and hygromycin.

Oligodendrocytes, myelin forming glia cells, are the primary cells affected in MLD. Therefore, direct gene transfer into oligodendrocytes is another important strategy for the gene therapy of MLD. However, reliable vectors for targeting stable gene transfer into neuronal cells have not yet been developed. Retroviral vectors are unable to integrate 
non-dividing cells (Naldini et al. 1996). Adenovirus vectors are capable of transferring genes into oligodendrocytes (Ohashi et al. 1995), but the gene expression is only transient. Nevertheless, it may be eventually be possible to use adeno-associated virus (AAV) vector (Berns and Giraud 1996; Daly et al. 1999), but the packaging system will need to be further refined before clinical use is possible (Trempe 1996). An additional disadvantage of direct vector injection is that it mediates gene transfer into only a very limited area. Because demyelination and accumulation of metachromatic granules occurs in all areas throughout the brain in MLD patients, direct injection would seems to be an insufficient treatment protocol. Accordingly, a combination of retrovirally mediated ex-vivo gene transfer into hematopoietic progenitor cells and AAV-mediated in-vivo gene transfer into neuronal cells may be important for the effective gene therapy of MLD.

Another potential option may be the use of neural stem cells as target cells of gene transfer, although there are many technical and ethical problem in this strategy. Methods have already been developed for transducing neural stem cells from rodents using retroviral vectors (Bloemer et al. 1996; Martinez-Serrano et al. 1995). Moreover, in canine multiple sclerosis model, focal demyelinations were prevented by transplantation of oligodendrocytes from normal embryonic dog (Archer et al. 1997). Recent technical developments have made it possible to purify and culture the human neural stem cells (Sah et al. 1997). Once the technical challenges associated with handling human neural stem cells are overcome, their transplantation combined with gene transfer could open the way to an effective new therapy of MLD.

Acknowledgments We wish to thank Dr. V Gieselmann (University of Kiel, Germany) for providing ASA cDNA, Dr. Sakuragawa (National institute of Neurology and Psychiatry, Tokyo, Japan) for providing skin fibroblasts from the patients with metachromatic leukodystrophy. We are also grateful to Kirin Brewers Co. (Tokyo, Japan) for providing IL-3 and IL-6, and Amgen (USA) for providing stem cell factor. This work was supported in part by a grants from Japanese Ministry of Health and Welfare (to M.M. and T.S.).

\section{References}

Archer DR, Cuddon PA, Lipsitz CD, Duncan ID (1997) Myelination of the canine central nervous system by glial cell transplantation: A model for repair of human myelin disease. Nature Medicine 3:54-59

Baum H, Dodgson KS, Spencer B (1959) The assay of arylsulfatase A and $\mathrm{B}$ in human urine. Clin Chimi Acta 4:453-455

Berns KI and Giraud C (1996) Biology of adeno-associated virus. In Berns KI and Giraud C eds. Adeno-associated virus (AAV) vector in gene therapy. Berlin:Springer-Verlag, 1-23

Bloemer U, Naldini L, Verma IM, Trono D, Gage FH (1996) Applications of gene therapy to the CNS. Human Mol. Genetics 5:1397-1404

Chalfie M, Tu Y, Euskirchen G, Ward WW, Prasher DC (1994) Green fluorescent protein as a marker for gene expression. Science 263:802805

Daly TM, Vogler C, Levy B, Haskins ME, Sands MS (1999) Neonatal gene transfer leads to widespread correction of pathology in a murine model of lysosomal storage disease. Pros. Natl. Acad. Sci. USA 96:2296-2300

Eglitis MA, Mezey E (1997) Hematopoietic cells differentiate into both microglia and macroglia in the brains of adult mice. Proc. Natl. Acad. Sci. USA 94:4080-4085

Hoogerbrugge PM, Brouwer OF, Bordigoni P (1995) Allogenic bone marrow transplantation for lysosomal storage diseases. Lancet 345:1398-1402

Kay R, Rosten PM, Humphries RK (1991) CD24, a signal transducer modulating B cell activation responses, is a very short peptide with a glycosyl phosphatidylinositol membrane anchor. J. Immunology 147:1412-1416

Kolodny EH, Fluharty AL (1995) Metachromatic leukodystrophy and multiple sulfatase deficiency: Sulfatide lipidosis. In Scriver CR, Beaudet AL, Sly WS, Valle D eds. The metabolic and molecular basis of inherited disease. 7th. eds. New York: McGraw-Hill Inc, 2693-2739

Krivit W, Lockman LA, Watkins J, Hirsch J, Shapiro EG (1995) The future for treatment by bone marrow transplantation for adrenoleukodystrophy, metachromatic leukodystrophy, globoid cell leukodystrophy and Hurler syndrome. J. Inher. Metabol. Dis. 18:398-412

Learish R, Ohashi T, Robbins PA, Bahnson A, Boggs SS, Patrene K, Schwartz BE, Gieselmann V, Barranger JA (1996) Retroviral gene transfer and sustained expression of human arylsulfatase A. Gene Therapy. 3:343-349

Malm G, Ringden O, Winiarski J, Grondahl E, Uvebrant P, Eriksson U, Harkansson H, Skejeldal O, Mansson J-E (1996) Clinical outcome in four children with metachromatic leukodystrophy treated by bone marrow transplantation. Bone marrow transplantation 17:1003-1008

Martinez-Serrano A, Lundberg C, Horellou P, Fischer W, Benlage C, Campbell K, McKay RDG, Mallet J, Bjorklund A (1995) CNSderived neural progenitor cells for gene transfer of nerve growth factor to the adult rat brain: complete rescue of axotomized cholinergic neurons after transplantation into the septum. J. Neurosci. 15:5668-5680

Migita M, Medin JA, Pawliuk R, Jacobson S, Nagle JW, Anderson S, Amiri M, Humphries RK, Karlsson S (1995) Selection of transduced CD34+ progenitors and enzymatic correction of cells from Gaucher patients, with bicistronic vectors. Proc. Natl. Acad. Sci. USA 92:12075-12079

Naldini L, Bloemer U, Gallay P, Ory D, Mulligan R, Gage FH, Verma IM, Trono D (1996) In vivo gene delivery and stable transduction of nondividing cells by a lentiviral vector. Science 272:263-267

Neufeld EF (1991) Lysosomal storage diseases. Annu. Rev. Biochem. 60:257-280

Ohashi T, Watabe K, Sato Y, Saito I, Barranger JA, Eto Y (1995) Successful transduction of oligodendrocytes and restoration of arylsulfatase A deficiency in metabolic leukodystrophy fibroblasts using an adenovirus vector. Gene Therapy 2, 443-449

Olsen I, Dean M, Harris G, Muir H (1981) Direct transfer of a lysosomal enzyme from lymphoid cells to deficient fibroblasts. Nature 291:244-247

Pawliuk R, Kay R, Lansdorp P, Humphries RK (1994) Selection of retrovirally transduced

hematopoietic cell using CD24 as a marker of gene transfer. Blood 84:2868-2877

Pear WS, Nolan GP, Scott ML, Baltimore D (1993) Production of hightiter helper-free retroviruses by transient transfection. Proc. Natl. Acad. Sci. USA. 90:8392-8396

Persons DA, Allay JA, Alley ER, Smeyne RJ, Ashmun RA, Sorrentino BP, Nienhuis AW (1997) Retroviral-mediated transfer of the green fluorescent protein gene into murine hematopoietic cells facilitates scoring and selection of transduced progenitors in vitro and identification of genetically modified cells in vivo . Blood 90:1777-1786

Rommerskirch W, Fluharty AL, Perters C, von Figura K, Gieselmann V (1991) Restoration of arylsulfatase A activity in human-metachromatic-leukodystrophy fibroblasts via retroviral-vector-mediated gene transfer. Biochem. J. 280:459-461

Sangalli A, Taveggia C, Salviati A, Wrabetz L, Bordignon C, Severini G. (1999) Transduced fibroblasts and metachromatic leukodystrophy lymphocytes transfer arylsulfatase A to myelinating glia and deficient cells in vitro. Human Gene Therapy 9:2111-2119

Sah DWY, Ray J, Gage FH (1997) Biopotent progenitor cell lines from the human CNS. Nature biotechnol. 15:574-580

Stein C, Gieselmann V, Kreysing J, Schmidt B, Pohlman R, Waheed A, 
Meyer HE, O'Brien JS, von Figura K (1989) Cloning and expression of human arylsulfatase A. J. Biol. Chem 264:1252-1259

Trempe JP (1996) Packaging systems for adeno-associated virus vectors. Current topics in microbiology \& immunology 218:35-50
Xu L, Stahl SK, Blanco M, Schiffmann R, Dunbar C, Karlsson S (1995) Growth factors and stromal support generate very efficient retroviral transduction of peripheral blood CD34+ cells from Gaucher patients. Blood 86:141-146 